ARTICLE

DOI: $10.1038 / \mathrm{s} 41467-018-03853-1$

\title{
Matriptase-2 deficiency protects from obesity by modulating iron homeostasis
}

\author{
Alicia R. Folgueras ${ }^{1}$, Sandra Freitas-Rodríguez ${ }^{1}$, Andrew J. Ramsay ${ }^{1}$, Cecilia Garabaya ${ }^{1}$, Francisco Rodríguez ${ }^{1}$,
} Gloria Velasco ${ }^{1} \&$ Carlos López-Otín ${ }^{1}$

\begin{abstract}
Alterations in iron status have frequently been associated with obesity and other metabolic disorders. The hormone hepcidin stands out as a key regulator in the maintenance of iron homeostasis by controlling the main iron exporter, ferroportin. Here we demonstrate that the deficiency in the hepcidin repressor matriptase-2 (Tmprss6) protects from high-fat diet-induced obesity. Tmprss $6^{-1-}$ mice show a significant decrease in body fat, improved glucose tolerance and insulin sensitivity, and are protected against hepatic steatosis. Moreover, these mice exhibit a significant increase in fat lipolysis, consistent with their dramatic reduction in adiposity. Rescue experiments that block hepcidin up-regulation and restore iron levels in Tmprss6 ${ }^{-/-}$mice via anti-hemojuvelin (HJV) therapy, revert the obesity-resistant phenotype of Tmprss6 $6^{-/}$mice. Overall, this study describes a role for matritpase- 2 and hepcidin in obesity and highlights the relevance of iron regulation in the control of adipose tissue function.
\end{abstract}

\footnotetext{
${ }^{1}$ Departamento de Bioquímica y Biología Molecular, Facultad de Medicina, Instituto Universitario de Oncología del Principado de Asturias (IUOPA), Universidad de Oviedo, 33006 Oviedo, Spain. These authors contributed equally: Alicia R. Folgueras, Sandra Freitas-Rodríguez Correspondence and requests for materials should be addressed to A.R.F. (email: arfolgueras@uniovi.es) or to C.L.-O. (email: clo@uniovi.es)
} 
ypoferremia is commonly associated with chronic low-grade inflammatory conditions (anemia of inflammation), such as obesity ${ }^{1}$. Poor iron status is attributed to enhanced expression of the main iron regulatory hormone hepcidin in obese condition in response to the inflammatory stimuli ${ }^{2,3}$. Hepcidin blocks iron flux into the plasma by its direct binding to ferroportin, the principal iron exporter localized at the cell membrane of duodenal enterocytes, which absorb iron from the diet, and macrophages, which recycle iron from senescent erythrocytes. Hepcidin binding to ferroportin triggers its internalization and subsequent lysosomal degradation, thereby blocking iron export to the circulatory system ${ }^{4}$. In addition to inflammatory cytokines, high-iron levels also cause hepcidin up-regulation ${ }^{5}$. Importantly, iron overload has been associated with a variety of diseases and disorders frequently associated with obesity, such as hepatic steatosis, diabetes and insulin resistance ${ }^{6}$. Although hepcidin is mainly produced by the $\operatorname{liver}^{7-9}$, it has recently been described that other cell types such as adipocytes can produce hepcidin ${ }^{3}$. Moreover, it has been shown that adipocytes also express ferroportin and that in vitro hepcidin treatment leads to its down-regulation in this cell type. Interestingly, the consequences of iron deregulation in adipose tissue have recently been linked to alterations in adipokine secretion and insulin resistance ${ }^{10-12}$.

Previously, we demonstrated that matriptase- 2 (encoded by Tmprss6), a type II transmembrane serine protease, is a repressor of hepcidin expression ${ }^{13}$. Mice deficient in matriptase-2, or lacking the proteolytic domain of this enzyme (mask mice), develop hypochromic microcytic anemia as a result of the abnormally elevated levels of hepcidin expression in the liver and the decreased ferroportin expression in duodenal cells ${ }^{13-18}$. In humans, mutations in TMPRSS6 cause iron-refractory iron deficiency anemia (IRIDA), characterized by no hematological improvement following treatment with oral iron ${ }^{19-22}$. The primary aim of this study was to investigate whether matriptase2 , a negative regulator of hepcidin, may influence obesity development and its associated pathological conditions. We find that matriptase- 2 deficiency protects from high-fat diet-induced obesity by increasing fat lipolysis, a phenotype which is dependent on the inadequate hepcidin up-regulation and iron imbalance characteristic of Tmprss $6^{-1-}$ mice.

\section{Results}

Matriptase-2 loss protects against HFD-induced obesity. Hepcidin levels have been found to be increased in obese patients ${ }^{3}$. To determine whether the loss of a negative regulator of hepcidin plays a significant role in the development of an obese phenotype, we fed wild-type and Tmprss $6^{-1-}$ mice a high-fat diet (HFD) for 20 weeks after weaning. In addition, to evaluate the specific contribution of the hypoferremic phenotype of Tmprss $6^{-1-}$ mice in the outcome of the experiment, we treated Tmprss $6^{-1-}$ mice with intraperitoneal injections of iron-dextran to revert their plasma iron deficiency. As shown in Supplementary Fig. 1, this treatment resulted in a marked rescue of most of the hematologic parameters characteristic of IRIDA, which are found in Tmprss $6^{-1-}$ mice. However, iron-treated Tmprss6 $6^{-1-}$ mice showed systemic and tissue iron levels above those found in wild-type mice (Fig. 1a and Supplementary Fig. 2 and 11). Therefore, as a control for iron overload in obesity and metabolic analysis, we also treated wild-type mice with intraperitoneal injections of iron-dextran in order to obtain similar iron levels to those observed in iron-treated Tmprss $6^{-1-}$ mice. Consistent with hepcidin regulation by iron ${ }^{8,23}$, the higher circulating iron levels found in both iron-treated Tmprss $6^{-1-}$ and Tmprss6 $6^{+/+}$mice further increased hepcidin expression over the abnormally high levels found in the absence of matriptase-2 (Fig. 1b). Interestingly, we observed that all experimental models showing high hepcidin levels (Tmprss $6^{-/-}$and iron-treated Tmprss $6^{-1-}$ mice, as well as iron-treated Tmprss6 $6^{+/+}$mice) showed significantly less body weight than wild-type controls after 20 weeks on a high-fat diet (Fig. 1c). Body weight of iron-treated Tmprss6 ${ }^{-1-}$ and Tmprss $6^{-1-}$ mice was decreased by $35 \%$ when normalized to their length, since the size of Tmprss $6^{-/-}$mice is slightly smaller ${ }^{13}$ and it is partially recovered after iron administration (Supplementary Fig. 3a, b). Thus, iron-treated Tmprss6 ${ }^{-1-}$ and Tmprss $6^{-/-}$mice gained $50 \%$ less weight than wild-type mice when challenged with a HFD (Supplementary Fig. 3c). The reduction in weight gain was more pronounced in iron-treated Tmprss $6^{+/+}$because of their higher weight at the onset of the experiment compared to Tmprss $6^{-1-}$ and iron-treated Tmprss 6 $-{ }^{-}$mice (Supplementary Fig. 3c). Moreover, analysis of body composition by MRI showed a significant decrease in the percentage of body fat in Tmprss $6^{-/-}$mice, which was further exacerbated by iron administration (Fig. 1d, e). Further, analysis of fat deposits demonstrated that fat pad weights normalized to total body weight was reduced in all compartments analyzed, including brown adipose tissue (BAT), in Tmprss6 $6^{-1-}$ mice and in both Tmprss6 $6^{-1-}$ and Tmprs6 $6^{+/+}$mice treated with iron compared with wild-type animals (Fig. 1f). In agreement with MRI analyses, the reduction in fat deposits was more pronounced in both iron-treated Tmprss6 $6^{-/-}$and Tmprss6 $6^{+/+}$mice than in Tmprss $6^{-1-}$ mice. Opposite to fat pads, the weight of other tissues normalized to total body weight was higher in $\operatorname{Tmprss}^{-/-}$mice and in both iron-treated Tmprss $6^{-/-}$and Tmprss $6^{+/+}$mice than in wild-type mice (Supplementary Fig. 3d). Altogether, our results indicate that the reduced weight gain observed in Tmprss $6^{-1-}$ mice and in both Tmprss6 $6^{-/-}$and Tmprss6 $6^{+/+}$mice treated with iron compared to wild-type mice is attributed to a lower fat content. Moreover, the analysis of lipid levels, frequently altered in obesity, showed a significant reduction in the concentration of plasma cholesterol in Tmprss6 $6^{-1-}$ mice and in both Tmprss6 $6^{-1-}$ and Tmprss $6^{+/+}$mice treated with iron compared with controls (Fig. 1g). However, we found that plasma triglycerides were lower in Tmprss $6^{-1-}$ mice, but not in both iron-treated Tmprss6 $6^{-1-}$ and Tmprss $6^{+/+}$mice, compared to wild-type mice (Fig. 1g).

Reduced adipocyte hypertrophy in the absence of matriptase-2. To better understand the observed reduction in fat deposits in Tmprss $6^{-/-}$mice upon high-fat feeding, we performed histological analyses of white (WAT) and brown adipose tissues. WAT analysis revealed a significant decrease in adipocyte cell size in Tmprss $6^{-1-}$ mice and in both iron-treated Tmprss $6^{-1-}$ and Tmprss $6^{+/+}$mice compared with wild-type animals (Fig. 2a, b). Accordingly, this reduction in adipocyte hypertrophy was accompanied by a concomitant increase in the number of adipocytes per area (Fig. 2a, b). Moreover, histological examination of BAT also showed a significant reduction in fat content in the absence of matriptase-2. Thus, iron-treated Tmprss6 ${ }^{-/-}$and Tmprss $6^{-1-}$ mice showed smaller and multilocular lipid droplets compared to wild-type controls (Fig. 2a, c), indicating that the observed resistance to the obesity-induced phenotype in Tmprss $6^{-1-}$ mice was not only related to a decrease in WAT hypertrophy, but also to a reduction in the lipid content of BAT. This phenotype was also observed in iron-treated Tmprss6 $6^{+/+}$ mice (Fig. 2a-c). Remarkably, analysis of the expression levels of genes involved in adipocyte differentiation, such as Cebpa, Srebf1, and Pparg, showed no major differences between wild-type and Tmprss6 $6^{-/-}$mice, suggesting that the observed changes in adipocyte size were not due to alterations in the main adipocyte differentiation program (Supplementary Fig. 4a, b). Of note, the 

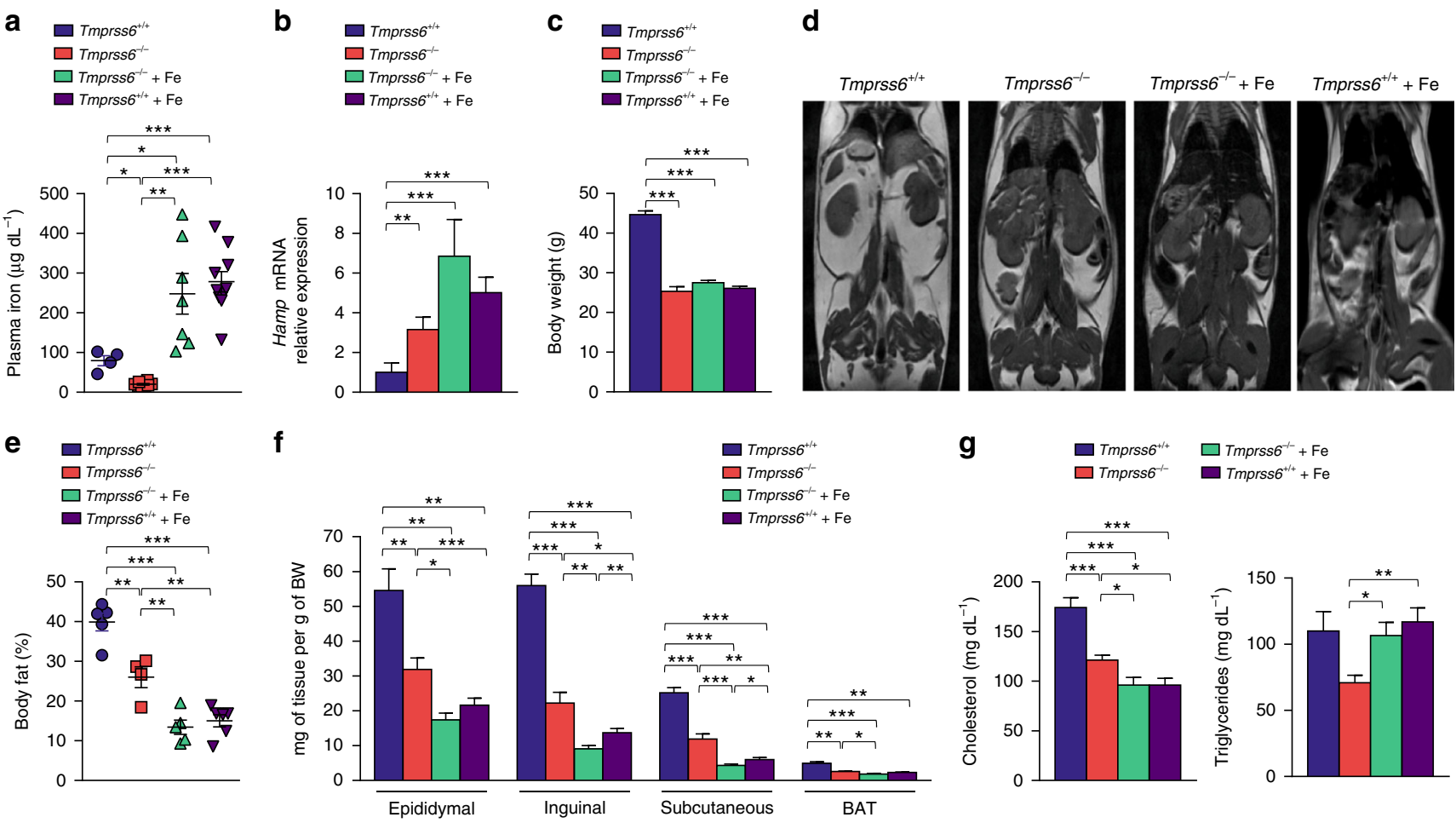

Fig. 1 Tmprss6-deficient mice are resistant to high-fat diet-induced obesity. a Fasting plasma concentration of iron in Tmprss $6^{+/+}(n=4)$, Tmprss6 $6^{-/-}$ $(n=8)$, and both iron-treated Tmprss6 $6^{-/-}$and Tmprss $6^{+/+}(n=7$ and $n=10$, respectively) mice fed a HFD for 20 weeks. b Relative gene expression of hepcidin (Hamp) in liver samples from HFD-fed Tmprss6 $6^{+/+}(n=11)$, Tmprss $^{-/-}(n=10)$, and both iron-treated Tmprss $6^{-/-}$and Tmprss $6^{+/+}$mice ( $n=10$ and $n=8$, respectively). c Body weight of Tmprss $6^{+/+}(n=7), \operatorname{Tmprss}^{-/-}(n=10)$, and both iron-treated Tmprss6 $6^{-/-}$and Tmprss $6^{+/+}$mice $\left(n=13\right.$ and $n=10$ respectively) fed a HFD for 20 weeks. d Representative MRI images across the body of Tmprss $6^{+/+}(n=5), \operatorname{Tmprss}^{-/-}(n=4)$, and both iron-treated Tmprss $6^{-/-}$and Tmprss $6^{+/+}$mice $(n=5$ and $n=6$ respectively) fed a HFD. White areas denote fat. e Body fat percentage was quantified by image analysis of MRI data on the same mice. $\mathbf{f}$ White adipose (epididymal, subcutaneous and inguinal) and brown adipose tissue (BAT) masses were determined relative to body weight from HFD-fed Tmprss6 $6^{+/+}(n=7)$, Tmprss6 ${ }^{-/-}(n=10)$, and both iron-treated Tmprss6 ${ }^{-/-}$and Tmprss6 $+/+$ mice $\left(n=12-13\right.$ and $n=10$ respectively). $\mathbf{g}$ Fasting plasma levels of cholesterol and triglycerides from HFD-fed Tmprss6 ${ }^{+/+}(n=7-9)$, Tmprss $^{-/-}$ $(n=8-9)$, and both iron-treated Tmprss6 ${ }^{-/-}$and Tmprss6 ${ }^{+/+}$mice $\left(n=9\right.$ and $n=9-10$ respectively). Data shown are mean \pm SEM. ${ }^{\star} P<0.05,{ }^{\star \star} P<0.01$, ${ }_{\star \star \star \star} P<0.001$, two-tailed Student's $t$ test and Mann-Whitney test

expression of some of these genes was down-regulated in those experimental groups where the reduction in body fat was more exacerbated, as in both Tmprss $6^{-/-}$and Tmprss $6^{+/+}$mice treated with iron.

To further explore those metabolic parameters that could be influenced by the loss of fat mass, we analyzed the levels of leptin, a key adipokine produced by the adipose tissue. These analyses revealed a striking reduction in plasma leptin concentration in the absence of matriptase- 2 and in the iron-treated experimental groups, all of them showing a lean phenotype, compared to wild-type mice (Fig. 2d). Thus, consistent with low leptin levels, Tmprss $6^{-/-}$mice and both iron-treated Tmprss $6^{-/-}$and Tmprss6 $+/+$ mice showed increased food intake compared with wild-type controls (Supplementary Fig. 3e). Therefore, these results demonstrated that the reduced weight gain observed in the absence of matriptase- 2 was not due to a lower appetite.

Decreased hepatic steatosis in Tmprss6 ${ }^{-1-}$ mice fed a HFD. Next, we analyzed whether matriptase- 2 deficiency also prevented the development of hepatic steatosis, a common disease frequently associated with obesity. Thus, Oil Red $\mathrm{O}$ staining of liver sections of HFD-fed mice showed a marked macrovesicular pattern of steatosis in wild-type mice (Fig. 3a). However, this macrovesicular pattern was not detected in $T m p r s s 6^{-/}$nor in both iron-treated Tmprss $6^{-/-}$and Tmprss $6^{+/+}$mice, indicating a clear reduction in liver lipid accumulation in the absence of matriptase-2 (Fig. 3a). Consistent with these findings, quantification of liver triglyceride content showed a significant reduction in triglyceride levels in Tmprss $6^{-/-}$mice and in both Tmprss6 $6^{-1-}$ and Tmprss $6^{+/+}$mice treated with iron compared with wild-type animals (Fig. 3b). To examine whether the observed reduction in lipid content was due to alterations in the hepatic lipid metabolism, we analyzed the expression levels of key genes involved in lipid synthesis and fatty acid oxidation. Surprisingly, we found a significant up-regulation in the expression levels of genes involved in de novo lipid synthesis, such as Fasn and Acaca, in Tmprss $6^{-1-}$ mice compared to wild-type mice (Fig. 3c). Furthermore, we found that the expression of one of the main regulators of fatty acid oxidation, such it is Cpt1a, was also increased in Tmprss $6^{-1-}$ mice (Fig. 3d). Interestingly, this up-regulation was not observed in iron-treated Tmprss $6^{-/}$animals, suggesting that the increased expression of diverse metabolic enzymes with opposite functions in the absence of matriptase- 2 is mainly caused by their hypoferremic phenotype, since iron treatment completely reverted the observed changes to wild-type levels. Nevertheless, in agreement with the observed histological and biochemical data, we found that the expression level of Pparg, a key driver of hepatic triglyceride storage ${ }^{24}$, was markedly down-regulated in Tmprss $6^{-1}-$ mice and in both iron-treated Tmprss6 $6^{-/-}$and Tmprss6 $6^{+/+}$mice compared to wild-type animals (Fig. 3e). This reduction was accompanied by a 
a
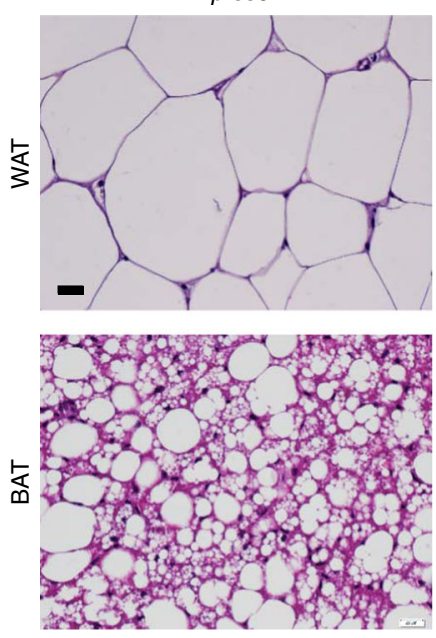

b

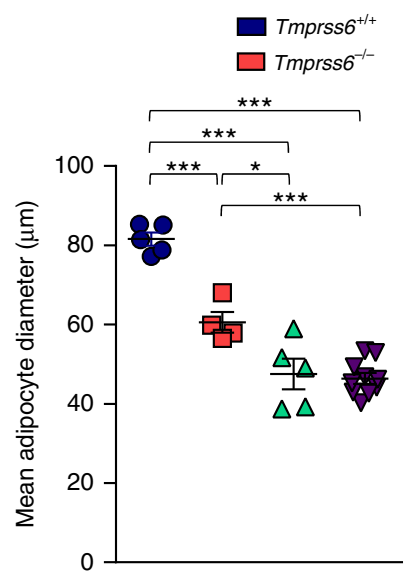

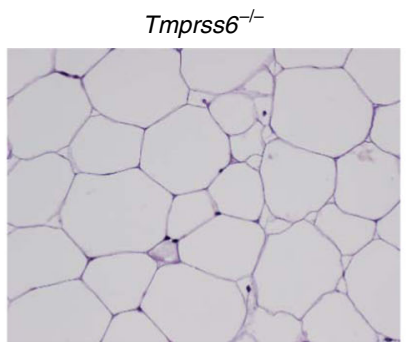
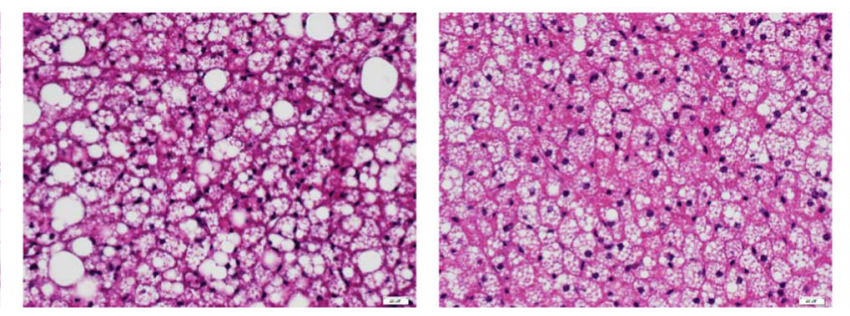

C
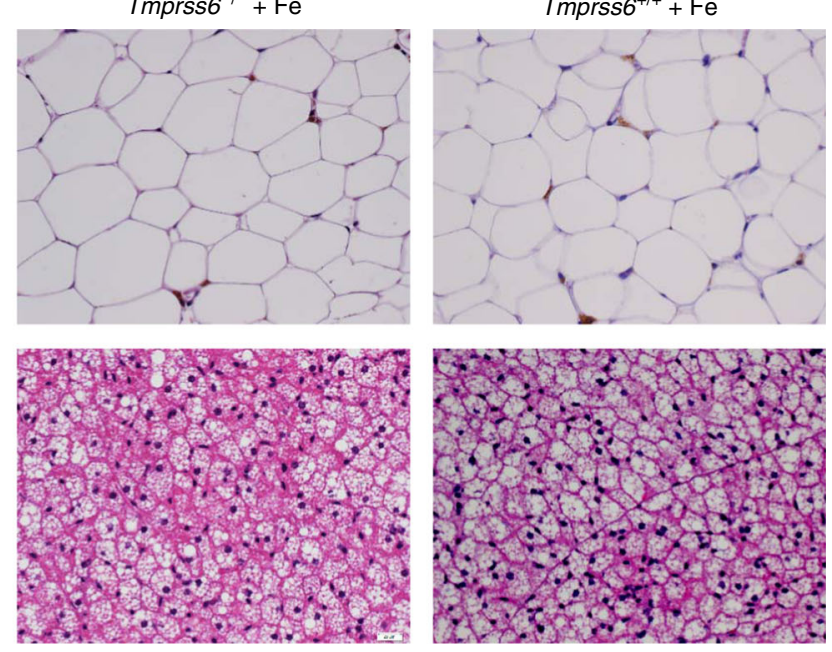

$\square$ Tmprss6 $^{-/}+\mathrm{Fe}$
$\square$ Tmprss6 $^{+/+}+\mathrm{Fe}$
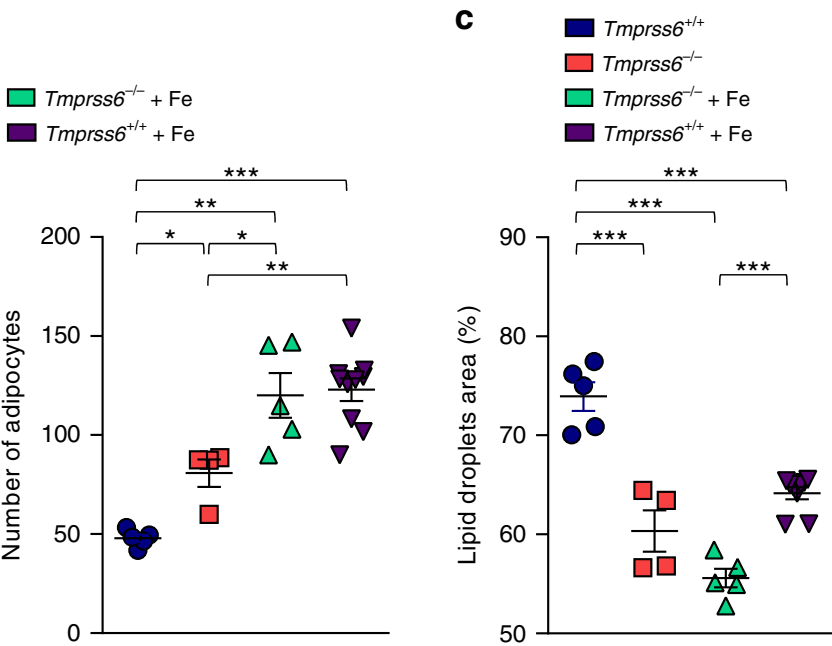
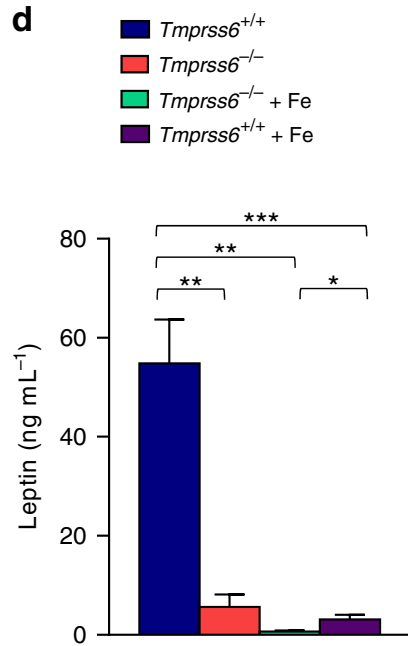

Fig. 2 Matriptase-2 deficiency prevents diet-induced adipocyte hypertrophy. a Representative images of epididymal fat pad and BAT sections stained with H\&E from Tmprss6 $6^{+/+}(n=5)$, Tmprss $6^{-/-}(n=4)$, and both iron-treated Tmprss $6^{-/-}$and Tmprss $6^{+/+}$mice $(n=5$ and $n=9-10$ respectively) fed a HFD for 20 weeks. b Size and number of epididymal adipocytes in Tmprss $6^{+/+}(n=5), \operatorname{Tmprss}^{-/-}(n=4)$, and both iron-treated Tmprss $6^{-/-}$and Tmprss $^{+/+}$ mice $\left(n=5\right.$ and $n=10$, respectively). c Percentage of total area occupied by all lipid droplets in BAT sections stained with H\&E in Tmprss $6^{+/+}(n=5)$, Tmprss6 $6^{-/-}(n=4)$, and both iron-treated Tmprss6 $6^{-/-}$and Tmprss6 $6^{+/+}$mice $(n=5$ and $n=9$, respectively). $\mathbf{d}$ Fasting plasma concentration of leptin in Tmprss6 $6^{+/+}(n=6)$, Tmprss6 $^{-/-}(n=6)$, and both iron-treated Tmprss6 $6^{-/-}$and Tmprss6 $6^{+/+}$mice $(n=6$ and $n=9$, respectively $)$ fed a HFD. Scale bar $=20 \mu \mathrm{m}$. Data shown are mean \pm SEM. ${ }^{\star} P<0.05,{ }^{\star \star} P<0.01,{ }^{\star \star \star} P<0.001$, two-tailed Student's $t$ test and Mann-Whitney test

decrease in the expression level of the Pparg downstream target Fsp27/CIDEC, encoding a lipid-droplet associated protein that promotes lipid accumulation, in both iron-treated Tmprss $6^{-/-}$and Tmprss6 $6^{+/+}$mice compared to wild-type animals (Fig. 3e).

Improved glucose homeostasis in Tmprss6 ${ }^{-/-}$mice fed a HFD. The striking resistance to the development of an obese phenotype observed in the absence of matriptase-2, prompted us to evaluate whether matriptase-2 deficiency also affected glucose homeostasis. Thus, consistent with the reduced fat content, we found lower plasma insulin levels in Tmprss $6^{-1-}$ mice and in both irontreated Tmprss $6^{-/-}$and Tmprss6 $6^{+/+}$mice compared with wild-type mice, suggesting the possibility of improved insulin sensitivity in the absence of matriptase-2 (Fig. 4a). Accordingly, the concentration of fasting blood glucose was significantly reduced in both iron-treated Tmprss $6^{-/-}$and Tmprss $6^{+/+}$mice, in which the resistance to diet-induced obesity was more exacerbated, but not in Tmprss $6^{-/-}$mice compared with wildtype mice (Fig. 4b). Interestingly, analysis of the expression levels of key hepatic gluconeogenic and glycolytic genes, such as Pck1 and

$P f k 1$, revealed a significant up-regulation of these genes in Tmprss $6^{-1-}$ mice compared to those found in wild-type mice (Fig. 4c, d). However, similarly to what we observed in the analysis of genes involved in the regulation of lipid metabolism, this up-regulation of enzymes belonging to opposite metabolic routes was ameliorated or completely reverted in iron-treated Tmprss $6^{-1-}$ mice (Fig. 4c, d). Altogether, these results suggest that the observed deregulation in the expression levels of both gluconeogenic and glycolytic genes in Tmprss6 ${ }^{-1-}$ mice is a consequence of their iron deficiency, which may explain why glucose levels are not decreased in these mice compared with wild-type animals despite their leaner phenotype. Nevertheless, to further explore glucose homeostasis in the absence of matriptase2 , we performed glucose tolerance tests by intraperitoneal administration of glucose to the mice. These experiments revealed 

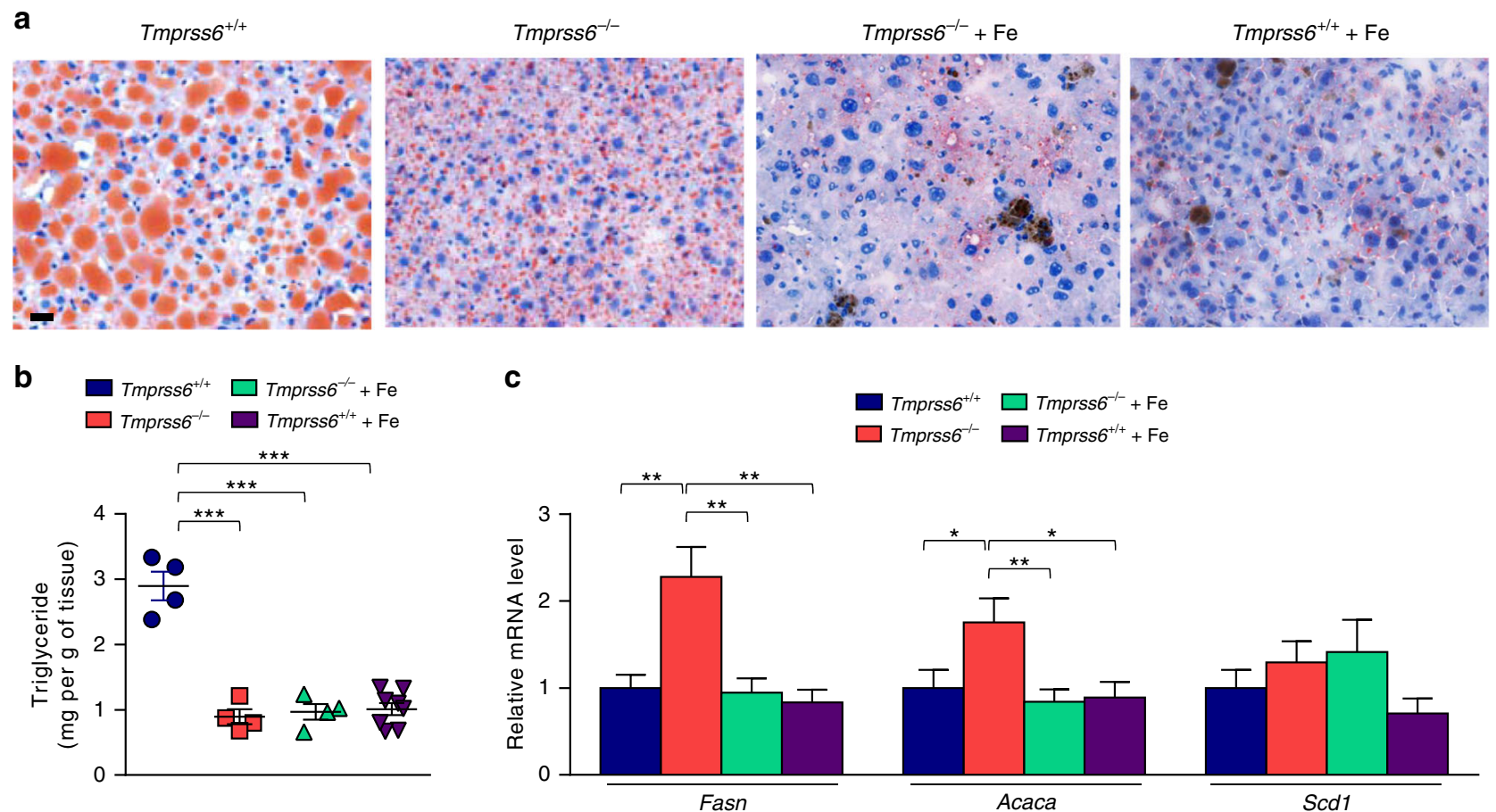

d
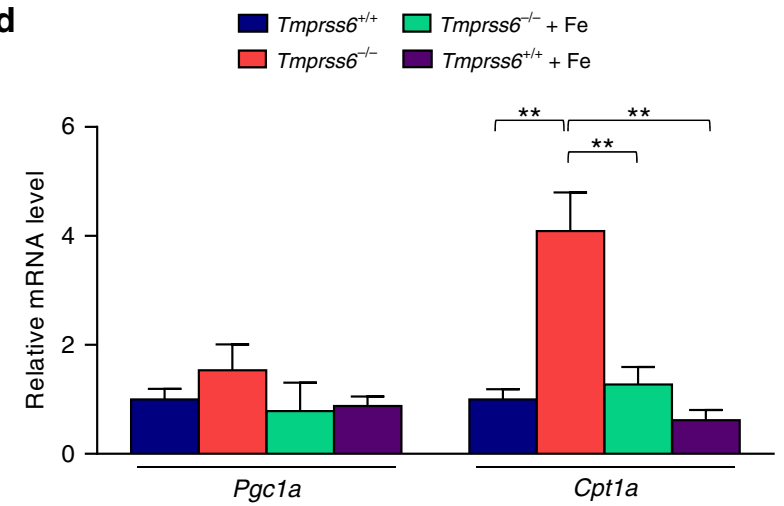

$\mathbf{e}$

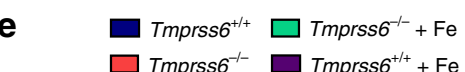

$\square$ Tmprss6 $^{+/+} \square$ Tmprss6 $^{-/}+\mathrm{Fe}$
$\square$ Tmprss6 $^{-/-} \square$ Tmprss6

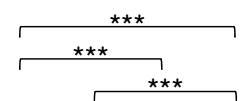

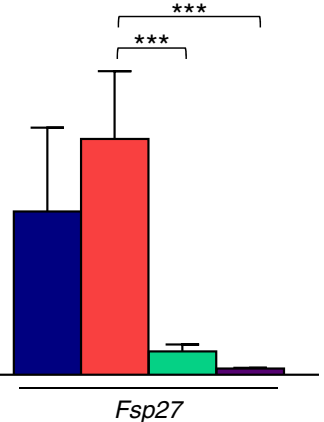

Fig. 3 Matriptase-2 loss impairs hepatic steatosis upon HFD feeding. a Representative Oil Red O staining of liver sections from Tmprss $6^{+/+}(n=4)$, Tmprss6 $6^{-/}(n=4)$, and both iron-treated Tmprss6 ${ }^{-/-}$and Tmprss6 ${ }^{+/+}$mice $(n=4$ and $n=8$, respectively) fed a HFD. $\mathbf{b}$ Triglyceride content of liver samples from HFD-fed Tmprss6 $6^{+/+}(n=4), \operatorname{Tmprss}^{-/-}(n=4)$, and both iron-treated Tmprss6 ${ }^{-/-}$and Tmprss6 ${ }^{+/+}$mice $(n=4$ and $n=8$, respectively). Relative expression levels of genes related to lipogenesis (c), $\beta$-oxidation (d), and lipid storage (e) in liver samples from HFD-fed Tmprss $6^{+/+}(n=11)$, Tmprss $^{-/-}(n=8-10)$, and both iron-treated Tmprss $6^{-/-}$and Tmprss $6^{+/+}$mice $(n=9-10$ and $n=7-8$ respectively). Scale bar $=20 \mu m$. Data shown are mean \pm SEM. ${ }^{\star} P<0.05,{ }^{\star \star} P<0.01,{ }^{\star \star \star}{ }^{*} P<0.001$, two-tailed Student's $t$ test and Mann-Whitney test

a significant improved glucose clearance in Tmprss6 $6^{-1-}$ and irontreated Tmprss6 $6^{-1-}$ mice compared with wild-type animals (Fig. 4e). Similarly, blood glucose levels decreased more rapidly in knock-out mice upon insulin injection, indicating increased insulin sensitivity in these mice, which is consistent with their lower insulin levels (Fig. 4f). Remarkably, iron treatment partially increased insulin resistance of Tmprss $6^{-1-}$ mice, although this resistance did not reach wild-type levels. Similar results were also observed in iron-treated Tmprss $6^{+/+}$mice. These findings are in agreement with a deleterious role of iron on adipose tissue function $^{10}$. Altogether, these results demonstrate that matriptase2-deficiency protects against the development of glucose intolerance and insulin resistance associated with diet-induced obesity, probably as a consequence of their decreased fat mass.

Increased fat lipolysis in Tmprss6 $6^{-/}$mice fed a HFD. To determine the possible causes of the reduced adiposity observed in the absence of matriptase-2, we next analyzed mice energy expenditure by using indirect calorimetry. These experiments showed higher rates of oxygen consumption and $\mathrm{CO}_{2}$ production adjusted for lean mass in Tmprss $6^{-/}$mice compared with wildtype mice during both light and dark phases (Supplementary Fig. 5a, b). Accordingly, energy expenditure was significantly increased in these mice (Supplementary Fig. 5c). Remarkably, iron treatment completely reverted this phenotype. Thus, irontreated Tmprss $6^{-1}$ mice showed similar energy expenditure than wild-type mice (Supplementary Fig. 5c), suggesting that the observed alterations in the absence of matriptase- 2 could be a consequence of the hypoferremic phenotype. These changes occurred in the absence of a significant increase in the locomotor activity or the expression levels of thermogenic genes in BAT samples of Tmprss6 $6^{-1-}$ mice compared to those found in wildtype mice (Supplementary Fig. 5d, 6). Taken together, these data suggest that energy balance might not be the main mechanism responsible for the observed resistance to diet-induced obesity in 
a
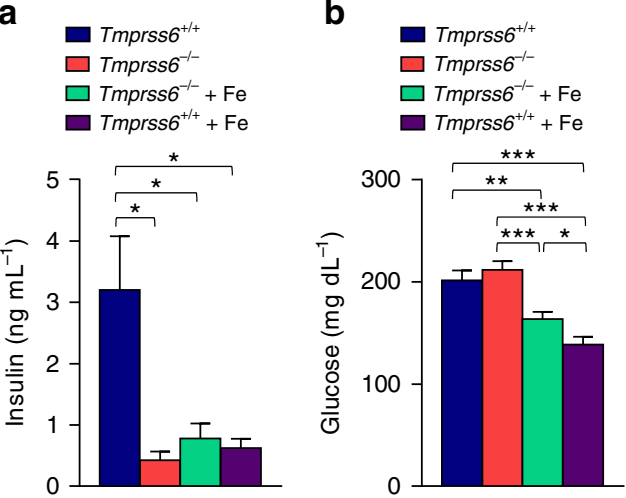

b c

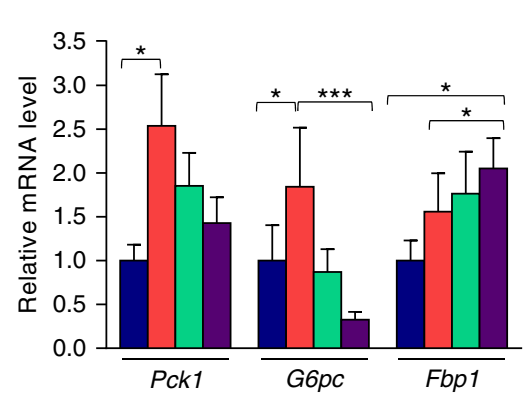

d

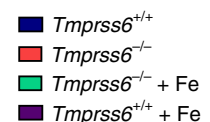

$\square$ Tmprss6 $^{-/-}+\mathrm{Fe}$

$\square$ Tmprss6 $^{+/+}+\mathrm{Fe}$ d
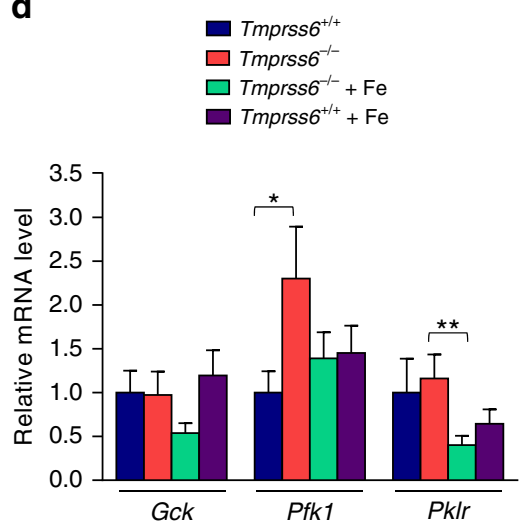

e

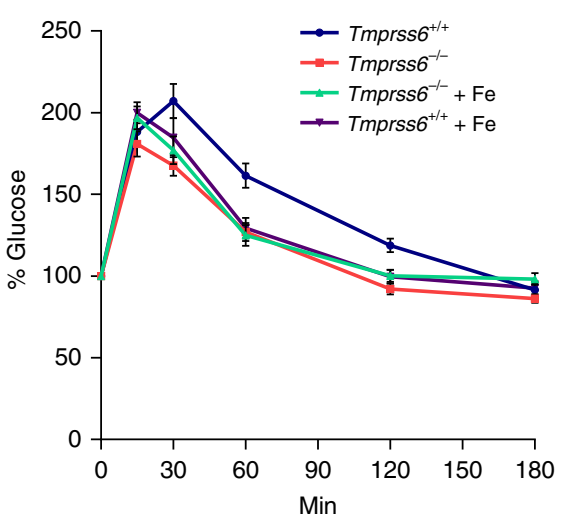

$\mathbf{f}$
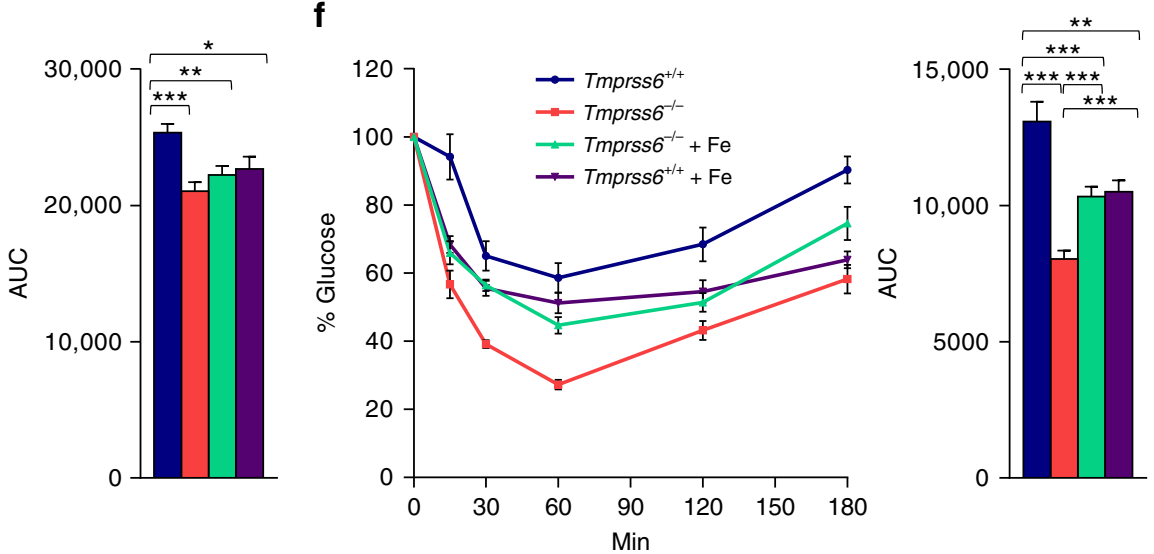

Fig. 4 Improved glucose metabolism in HFD-fed Tmprss6-deficient mice. a Fasting plasma concentration of insulin in HFD-fed Tmprss6 ${ }^{+/+}(n=10)$, Tmprss $6^{-/-}(n=6)$, and both iron-treated Tmprss $6^{-/-}$and Tmprss $6^{+/+}$mice $(n=8$ and $n=6$ respectively). b Fasting blood glucose concentration in HFD-fed Tmprss6 $\sigma^{+/+}(n=11)$, Tmprss6 $6^{-/-}(n=13)$, and both iron-treated Tmprss6 $6^{-/-}$and Tmprss6 $6^{+/+}$mice $(n=13$ and $n=10$ respectively). Relative expression levels of genes related to gluconeogenesis (c) and glycolysis (d) in liver samples from HFD-fed Tmprss6 ${ }^{+/+}(n=11)$, Tmprss6 $6^{-/-}(n=8-9)$, and both iron-treated Tmprss $6^{-/-}$and Tmprss $6^{+/+}$mice $(n=10-11$ and $n=8$ respectively). e Glucose tolerance test after overnight fasting in HFD-fed Tmprss6 $^{+/+}(n=11)$, Tmprss6 $^{-/-}(n=12)$, and both iron-treated Tmprss6 $6^{-/-}$and Tmprss6 ${ }^{+/+}$mice $(n=9$ and $n=9$ respectively). $\mathbf{f}$ Insulin tolerance test after overnight fasting in HFD-fed Tmprss6 $6^{+/+}(n=11)$, Tmprss6 ${ }^{-/-}(n=12)$, and both iron-treated Tmprss $6^{-/-}$and Tmprss $6^{+/+}$mice $(n=13$ and $n=11$ respectively). AUC, area under the curve. Data shown are mean \pm SEM. ${ }^{\star} P<0.05,{ }^{\star \star} P<0.01,{ }^{\star \star \star} P<0.001$, two-tailed Student's $t$ test and Mann-Whitney test

the absence of matriptase-2, since iron-treated $\operatorname{Tmprss}^{-1}{ }^{-}$mice behave similar to wild-type mice in this regard but show a marked lean phenotype. Therefore, to get further insights into the mechanisms that could explain the reduced fat content of Tmprss $6^{-1-}$ and iron-treated Tmprss $6^{-1-}$ mice, we analyzed the expression levels of the main genes responsible for the hydrolysis of stored lipids in adipocytes in WAT samples. Notably, we found a significant increase in Pnpla2 (adipose triglyceride lipase, ATGL) gene expression in Tmprss $6^{-1}$ - mice compared to those in wild-type mice (Fig. 5a), which was further confirmed at the protein level (Fig. 5b and Supplementary Fig. 11). ATGL protein concentration was also significantly elevated in iron-treated Tmprss $6^{-1-}$ mice (Fig. 5b and Supplementary Fig. 11). No differences were detected in the expression level of the lipolytic gene Lipe (hormone-sensitive lipase, HSL), but we observed a significant increase in the expression level of $A d r b 3$ ( $\beta 3$-adrenergic receptor) in Tmprss $6^{-/-}$and iron-treated Tmprss $6^{-1-}$ mice compared to wild-type mice (Fig. 5a), being $\beta$-adrenergic signaling one of the main pathways responsible for the control of HSL activity and fat mobilization in the adipose tissue ${ }^{25}$. Thus, $\beta-$ adrenergic stimulation leads to the phosphorylation of HSL, which increases the hydrolytic activity of the enzyme against triacylglycerol substrate ${ }^{26}$. Considering that HSL is primarily regulated by post-translational mechanisms rather than at the mRNA level, we were prompted to analyze the phosphorylation status of HSL in WAT samples. Western-blot analysis revealed a striking increase in phospho-HSL levels versus total HSL protein in Tmprss $6^{-1}$ and iron-treated Tmprss $6^{-1-}$ mice compared with wild-type mice (Fig. 5b and Supplementary Fig. 11). Interestingly, HSL phosphorylation was also significantly elevated in irontreated Tmprss $6^{+/+}$mice (Fig. 5b and Supplementary Fig. 11).

Taken together, these results suggest that the reduced adiposity observed in matriptase- 2 deficient mice, with and without iron supplementation, is due to an increased lipolysis triggered by the two main lipolytic enzymes, HSL and ATGL. In addition, we found that HSL phosphorylation and ATGL concentration were increased in iron-treated Tmprss $6^{+/+}$mice, suggesting a relevant role for the lipolytic pathway in these mice that also show a significant reduction in their fat mass compared to wild-type mice.

Hepcidin down-regulation induces obesity in Tmprss6 $6^{-1-}$ mice. Considering that adipocyte iron deregulation has recently been associated to alterations in adipokine secretion and insulin resistance ${ }^{10-12}$, we next asked if variations in adipocyte iron 
a

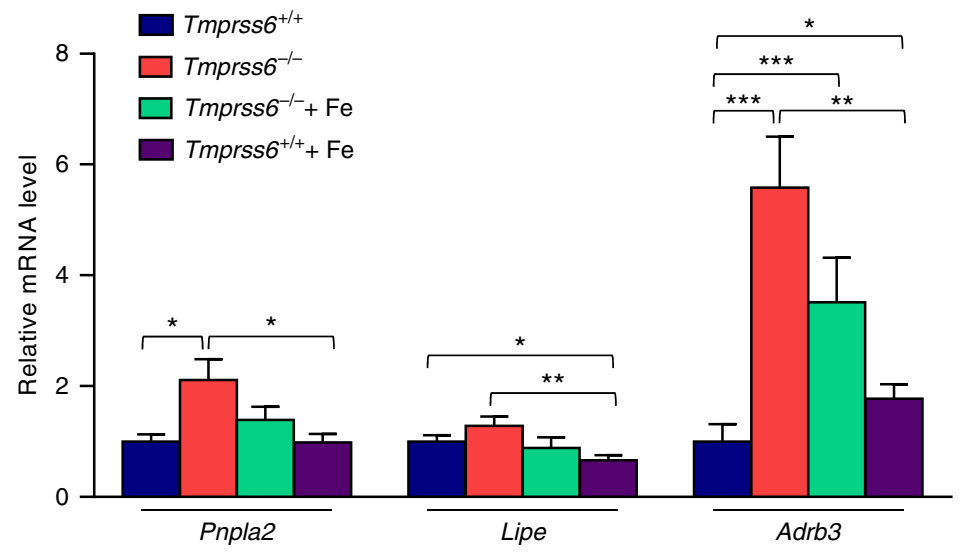

b
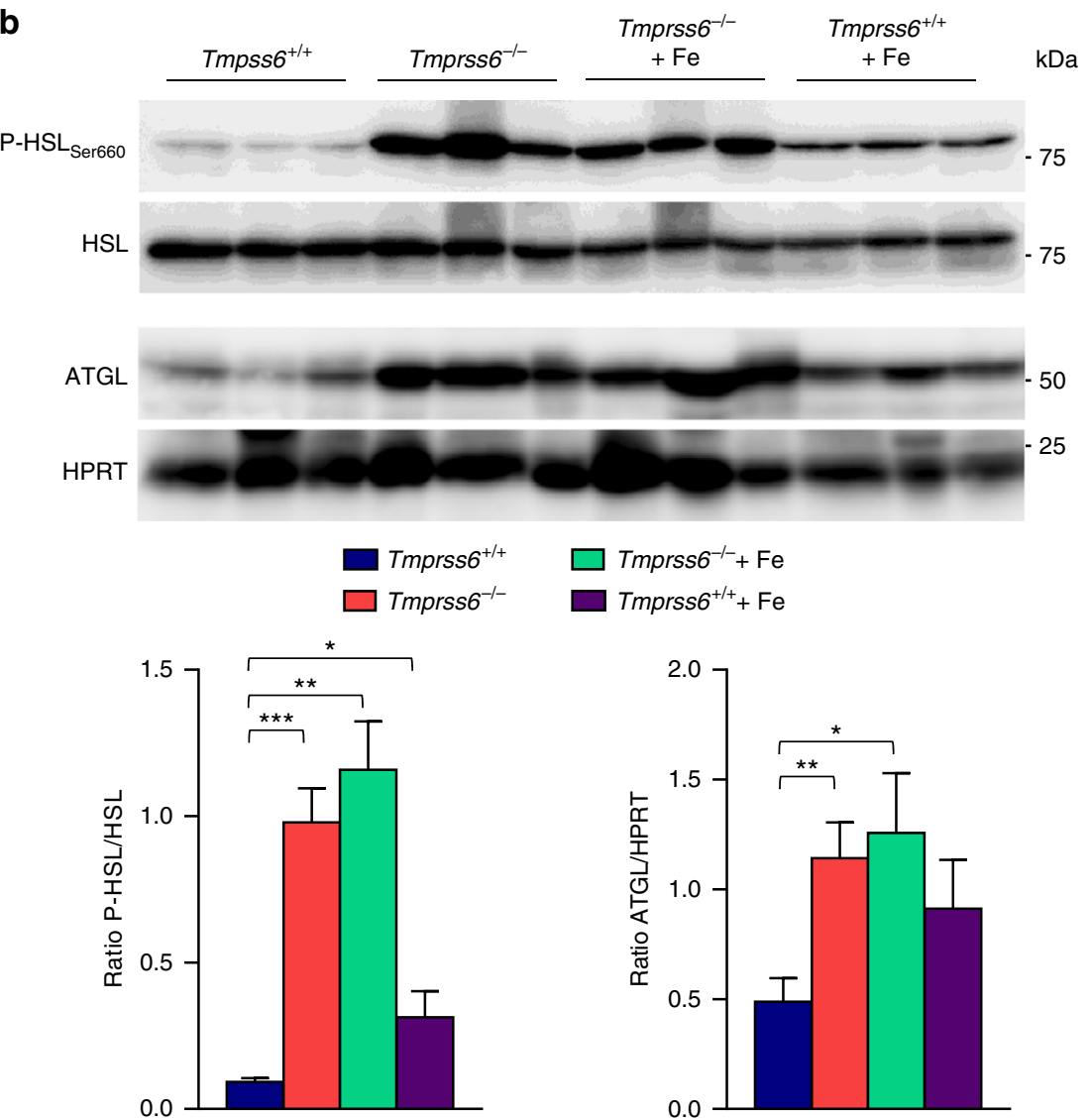

Fig. 5 Increased WAT lipolysis in mice lacking matriptase-2 upon HFD feeding. a Relative expression levels of genes related to lipolysis in WAT samples from HFD-fed Tmprss6 $6^{+/+}(n=11)$, Tmprss6 $\sigma^{-/-}(n=7)$, and both iron-treated Tmprss6 $6^{-/-}$and Tmprss $6^{+/+}$mice $(n=11$ and $n=8$, respectively). b Western-blot analysis of phospho-HSL(Ser660), total HSL and ATGL protein expression in WAT samples from HFD-fed Tmprss6 ${ }^{+/+}(n=6)$, Tmprss $^{-/-}(n=6)$, and both iron-treated Tmprss $6^{-/-}$and Tmprss $6^{+/+}$mice $(n=6$ and $n=7$ respectively). (top) A representative result showing increased phospho-HSL and ATGL protein levels in Tmprss $6^{-/-}$and both iron-treated Tmprss $6^{-/-}$and Tmprss $6^{+/+}$mice compared to wild-type mice. (bottom) Quantification of phospho-HSL protein levels relative to total HSL levels and ATGL protein levels relative to loading control HPRT (hypoxanthineguanine phosphoribosyltransferase). Note that phospho-HSL and the corresponding loading control, the total HSL protein, were detected on the same samples run in parallel in two identical blots. Data shown are mean \pm SEM. ${ }^{\star} P<0.05,{ }^{\star \star} P<0.01,{ }^{\star \star \star} P<0.001$, two-tailed Student's $t$ test and Mann-Whitney test

content may also influence the lipolytic program of the adipose tissue of matriptase- 2 deficient mice. To this end, we measured iron levels in adipocytes isolated from WAT samples obtained from all experimental groups. No differences were observed in the iron content of adipocytes from Tmprss $6^{-1-}$ and iron-treated Tmprss $6^{-/-}$mice compared to wild-type mice. Remarkably, the excess of iron of both Tmprss $6^{-/-}$and Tmprss $6^{+/+}$mice treated with iron was mostly accumulated in the stromal-vascular fraction (SVF) of the adipose tissue, which contains a high percentage of infiltrating macrophages, rather than in the adipocytes themselves (Supplementary Fig. 7).

On the basis of the high hepcidin levels found in the three experimental groups with a leaner phenotype, Tmprss $6^{-1-}$ and both iron-treated Tmprss $6^{-/-}$and Tmprss $6^{++}$mice, we further 


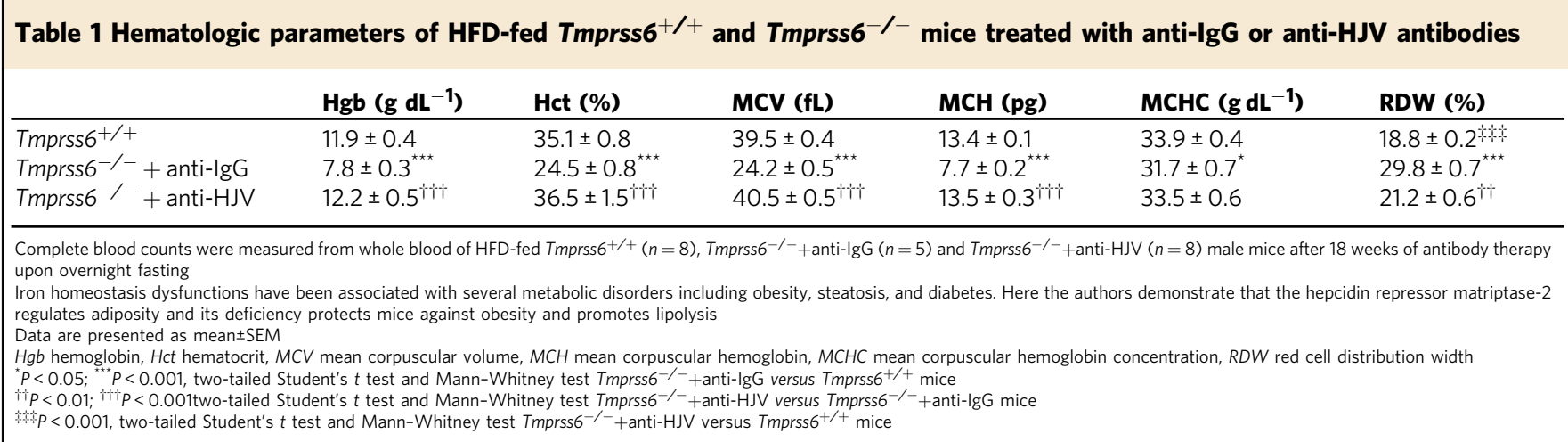

investigated whether hepcidin up-regulation might be responsible for the induction of lipolysis and the HFD-obesity resistance phenotype observed in matriptase- 2 deficient mice. To test this hypothesis, we aimed at blocking hepcidin up-regulation in Tmprss $6^{-/}$mice by using a neutralizing antibody against hemojuvelin (HJV), a molecule that acts as a co-receptor of the BMP (bone morphogenetic protein) signaling pathway that promotes hepcidin transcription ${ }^{27}$. We treated weekly Tmprss6 ${ }^{-} /{ }^{-}$mice with an anti-HJV neutralizing antibody or control antiIgG for 18 weeks. Thus, mice were treated for the first time at the age of 6 weeks, two weeks after weaning and the onset of HFD administration, and the treatment lasted until the time of sacrifice. As shown in Supplementary Fig. 8, the monitoring of plasma hematologic parameters over time showed a rapid rescue of Hgb levels in anti-HJV-treated Tmprss $6^{-1-}$ mice compared to those injected with control anti-IgG after two weeks of treatment. This recovery was also observed in the rest of hematologic parameters analyzed, which peaked 4 weeks after the onset of the antibody therapy and it was sustained during the whole treatment period, reaching wild-type levels in anti-HJV-treated Tmprss6 ${ }^{-} /-$mice (Table 1 ). Consistent with these data, anti-HJV therapy also restored the hair coat of Tmprss $6^{-1-}$ mice as a result of the recovery of plasma iron levels ${ }^{13}$ (Fig. $6 \mathrm{a}, \mathrm{c}$ ). The analysis of liver samples from this experimental setting allowed us to confirm the significant reduction of hepcidin expression in anti-HJV-treated Tmprss6 $6^{-1-}$ mice compared to anti-IgG-treated Tmprss6 $6^{-1-}$ mice, thereby demonstrating the efficacy of the anti-HJV therapy (Fig. 6b). Consistent with the restoration of systemic iron levels upon hepcidin down-regulation, the concentration of plasma ferritin significantly increased in anti-HJV-treated Tmprss6 ${ }^{-/}$mice compared to anti-IgG-treated Tmprss $6^{-/-}$mice, reaching wild-type levels (Supplementary Fig. 9a). In agreement, we observed a significant increase in the liver iron content of antiHJV-treated Tmprss $6^{-/-}$mice compared to the anti-IgG control group, which was accompanied by a down-regulation of the transferrin receptor 1 (Tfrc, TfR1) mRNA levels and protein expression in this tissue (Supplementary Fig. 9b-d and 11). More important, hepcidin down-regulation in anti-HJV-treated Tmprss $6^{-/}$mice completely abolished the obesity-resistant phenotype observed in matriptase- 2 deficient mice on HFD diet. Thus, anti-HJV-treated Tmprss $6^{-1-}$ mice gain significantly more weight than anti-IgG-treated Tmprss $6^{-1-}$ mice (Fig. 6d). Further, analysis of fat deposits in these mice demonstrated that the weight gain was due to a significant increase in the adiposity of anti-HJV-treated Tmprss6 $6^{-/-}$versus anti-IgG-treated mice (Supplementary Fig. 10). This increase in the adiposity was accompanied by a marked adipocyte hypertrophy of WAT samples and a significant increase in leptin production in antiHJV-treated Tmprss $6^{-/-}$mice compared to anti-IgG treated Tmprss $6^{-/}$mice (Fig. 6e-g). Hepdicin down-regulation also resulted in a marked liver steatosis in anti-HJV-treated Tmprss $6^{-/-}$mice (Fig. 6h, i). Furthermore, we found that hepdicin down-regulation in matriptase-2 deficient mice through anti-HJV therapy completely reverted the lipolytic program of the adipose tissue to wild-type levels (Fig. 6j, k and Supplementary Fig. 11)

Altogether, these data yield insights into the mechanism responsible for the obesity-resistant phenotype of matripase-2 deficient mice, providing functional evidence of the prominent role of hepcidin in the regulation of lipid metabolism.

\section{Discussion}

The role of iron and its main regulatory hormone hepcidin in obesity is still unclear. On the one hand, epidemiological studies have associated elevated hepcidin levels and iron deficiency with obesity $^{3}$. These studies suggest that increased hepcidin concentrations occur as a result of the chronic inflammatory condition linked to obese individuals, which ultimately leads to defective intestinal iron absorption and anemia ${ }^{2}$. On the other hand, iron overload, which also triggers hepcidin up-regulation, has been associated with fatty-liver disease, diabetes and insulin resistance, three common conditions frequently associated with obesity $^{28,29}$. In this work, we investigated whether the in vivo deletion of a negative regulator of hepcidin, matriptase-2, contributes to the development of obesity and its pathogenic features. Thus, we challenged mice deficient in matriptase-2, whose phenotype is characterized by the anemia caused by the inadequate hepcidin up-regulation, with a protocol of diet-induced obesity. Further, we treated Tmprss $6^{-1-}$ mice with iron in order to determine the specific contribution of iron deficiency in the development of obesity within the same mouse model. However, this treatment resulted in higher systemic and tissue iron levels in iron-treated Tmprss $6^{-1-}$ mice compared to wild-type mice. Therefore, as a control for iron overload in the analysis of obesity and other metabolic parameters, we also treated wild-type mice with intraperitoneal injections of iron-dextran in order to obtain similar systemic and tissue iron levels as those observed in iron-treated Tmprss $6^{-1-}$ mice. A summary of the HFD-induced phenotypes of the different mouse models of iron imbalance and hepcidin up-regulation generated in this work is shown in Supplementary Table 1.

Our results demonstrate that both Tmprss $6^{-1-}$ and iron-treated Tmprss $6^{-1-}$ mice show a striking protection against body fat accumulation. Moreover, matriptase- 2 deficiency also prevents the development of hepatic steatosis, glucose intolerance and insulin resistance, all pathogenic processes associated with obesity. The relationship among hepcidin, iron overload and fatty-liver disease is still poorly understood. In humans, mutations in the HFE gene result in low hepcidin production and 
a

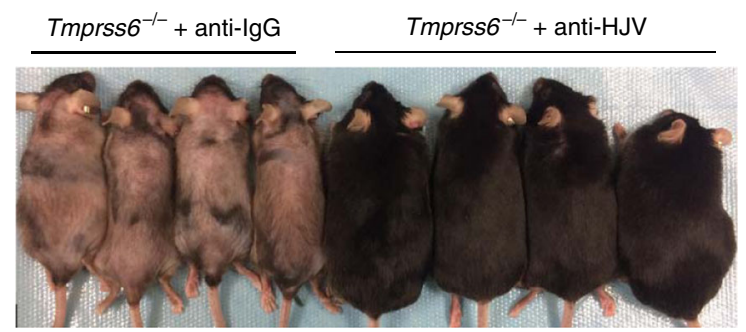

d

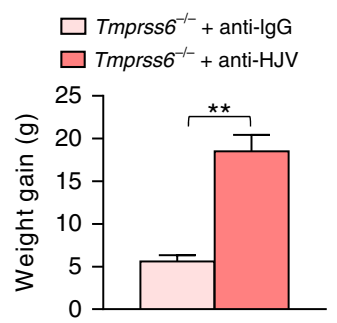

g

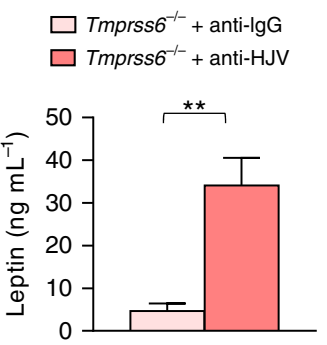

b

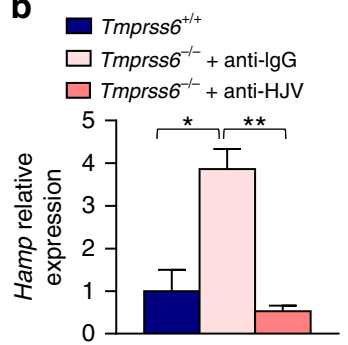

e Tmprss6 $^{-/-}+$anti-lgG

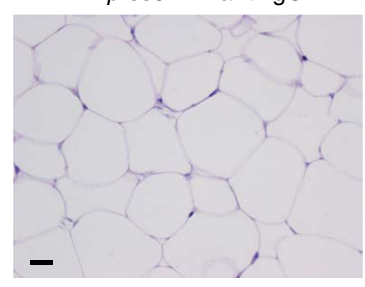

h Tmprss6 $^{-/-}+$anti-lgG

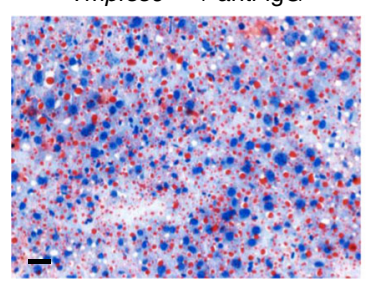

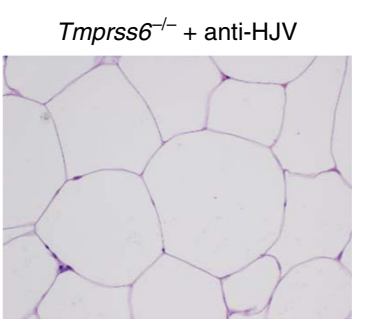

Tmprss6 $^{-1-}+$ anti-HJV

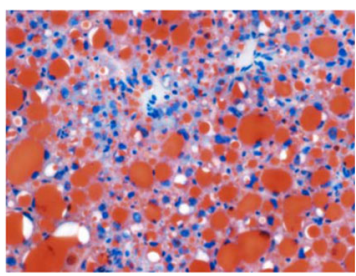

C

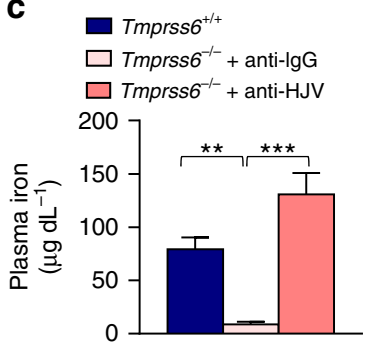

f

$$
\begin{aligned}
& \square \text { Tmprss6 }^{-/-}+\text {anti-lgG } \\
& \square \text { Tmprss6 }^{-/-}+\text {anti-HJV }
\end{aligned}
$$

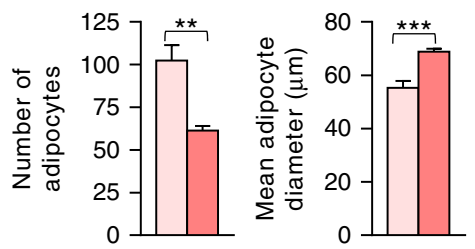

i

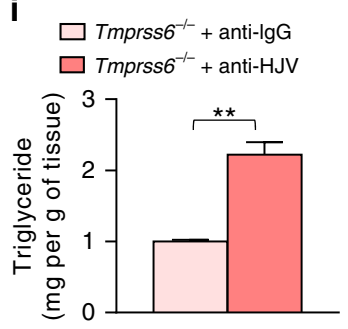

j

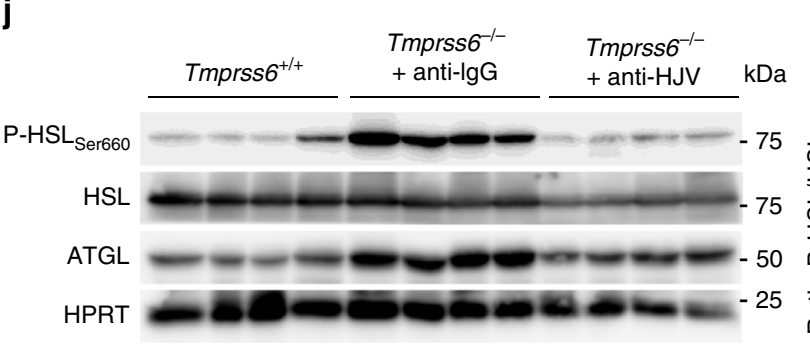

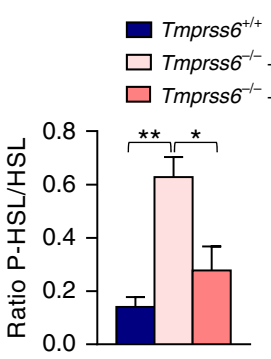

Tmprss6 $^{+/+}$

Tmprss6 $6^{-/-}+$anti-lgG $\square$ Tmprss6 $^{-1-}+$ anti-HJV

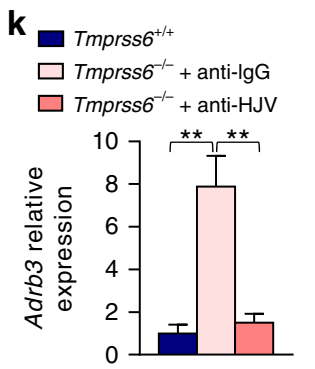

Fig. 6 Hepcidin down-regulation in Tmprss6-deficient mice reverts the obesity-resistant phenotype. a Representative image of HFD-fed Tmprss6 ${ }^{-/-}$mice treated weekly with anti-HJV neutralizing antibody or control anti-lgG for 18 weeks. The image shows the hair coat recovery and the increased body weight of anti-HJV-treated Tmprss6 $6^{-/-}$mice compared to Tmprss $^{-/-}$mice treated with control anti-lgG. b Relative gene expression of hepcidin (Hamp) in liver samples from HFD-fed Tmprss6 $6^{+/+}(n=7)$, anti-lgG-treated Tmprss6 ${ }^{-/-}(n=5)$, and anti-HJV-treated Tmprss6 $6^{-/-}(n=8)$ mice. c Fasting plasma concentration of iron in HFD-fed Tmprss $6^{+/+}(n=4)$, anti-lgG-treated Tmprss $6^{-/-}(n=5)$, and anti-HJV-treated Tmprss $6^{-/-}(n=8)$ mice. d Weight gain of anti-lgG-treated Tmprss6 ${ }^{-/-}(n=5)$, and anti-HJV-treated Tmprss6 $6^{-/}(n=8)$ HFD-fed mice after 18 weeks of antibody administration. e Representative images of epididymal fat pad sections stained with H\&E from HFD-fed anti-lgG-treated Tmprss6 $\sigma^{-/}(n=5)$ and anti-HJV-treated Tmprss6 $-/-(n=8)$ mice. $\mathbf{f}$ Number and size of epididymal adipocytes in HFD-fed anti-lgG-treated Tmprss6 $6^{-/}(n=5)$, and anti-HJV-treated Tmprss6 ${ }^{-/-}(n=8)$ mice. $\mathbf{g}$ Fasting plasma concentration of leptin in anti-lgG-treated Tmprss $6^{-/-}(n=5)$, and anti-HJV-treated Tmprss $6^{-/-}(n=8)$ mice fed a HFD. $\mathbf{h}$ Representative Oil Red O staining of liver sections from anti-lgG-treated Tmprss6 ${ }^{-/-}(n=5)$, and anti-HJV-treated Tmprss $6^{-/-}(n=8)$ mice fed a HFD. $\mathbf{i}$ Triglyceride content of liver samples from HFD-fed anti-lgG-treated Tmprss $6^{-/-}(n=5)$, and anti-HJV-treated Tmprss $6^{-/-}(n=8)$ mice. $\mathbf{j}$ Western-blot analysis of phospho-HSL(Ser660), total HSL and ATGL protein expression in WAT samples from HFD-fed Tmprss6 $6^{+/+}(n=5)$, anti-lgG-treated Tmprss6 $-/-(n=5)$, and anti-HJV-treated Tmprss6 ${ }^{-/}(n=8)$ mice. (left) A representative result showing decreased phospho-HSL and ATGL protein levels in antiHJV-treated Tmprss6 ${ }^{-/}$mice compared to anti-lgG-treated Tmprss6 ${ }^{-/}$-mice. (right) Quantification of phospho-HSL protein levels relative to total HSL levels and ATGL protein levels relative to loading control HPRT. Note that phospho-HSL and the corresponding loading control, the total HSL protein, were detected on the same samples run in parallel in two identical blots. k Relative gene expression of Adrb3 in WAT samples from HFD-fed Tmprss6 ${ }^{+/+}$ $(n=8)$, anti-lgG-treated Tmprss6 ${ }^{-/-}(n=5)$, and anti-HJV-treated Tmprss6 $6^{-/-}(n=8)$ mice. Scale bar $20 \mu m$. Data shown are mean \pm SEM. ${ }^{\star} P<0.05$, ${ }^{\star \star} P<0.01,{ }^{\star \star \star} P<0.001$, two-tailed Student's $t$ test and Mann-Whitney test

iron overload, being the most frequent form of hereditary hemochromatosis $(\mathrm{HH})^{30}$. A strong association has been found between patients with $\mathrm{HH}$ and nonalcoholic fatty-liver disease $(\mathrm{NAFLD})^{31,32}$. Also, mice deficient in $\mathrm{H} f e$ fed a HFD develop hepatic steatosis ${ }^{33}$. However, recent studies performed with hepcidin knock-out mice, which have a hepatic iron overload phenotype, show opposite results. Thus Hamp1 $1^{-/-}$mice develop attenuated steatosis compared to wild-types but increased liver fibrosis when fed a high fat and sucrose diet ${ }^{34}$. In this context, we found that both Tmprss $6^{-1-}$ mice, which display a marked 
hypoferremic phenotype due to inadequate hepcidin upregulation, and iron-treated Tmprss $6^{-1-}$ mice, which are no longer hypoferremic but still preserve high hepcidin levels, were protected against the development of hepatic steatosis. Furthermore, iron-treated wild-type mice, which also showed a significant hepcidin upregulation as a consequence of the exogenous iron administration, were equally protected against lipid accumulation in the liver. The fact that elevated hepcidin levels was the common mechanism shared by the three experimental groups, argued for a putative role of this peptide in the protection against the development of hepatic steatosis. Consistent with this hypothesis, our data demonstrate that blocking hepcidin up-regulation in Tmprss $6^{-1-}$ mice via anti-HJV therapy, completely reverted hepatic steatosis resistance in matriptase-2 deficient mice. The efficacy of hepcidin downregulation through the targeting of the BMP receptor signaling pathway had been previously demonstrated with the use of our mouse model ${ }^{18,35,36}$, which represents a valuable tool to test new therapies for patients suffering from anemia associated with inappropriate high hepcidin levels. However, further studies are needed to determine if hepcidin up-regulation alone is responsible for the observed phenotypes in the liver of irontreated mice or whether additional effects derived from iron deposition may account for the reduced hepatic steatosis observed under iron overload conditions.

The finding that a striking protection against body fat accumulation was observed in the absence of matriptase- 2 also supports the hypothesis of an indirect effect of this enzyme in the regulation of this process, since matriptase- 2 is not expressed in the adipose tissue. To date, besides clinical correlations between hepcidin/iron and obesity, very few studies have analyzed in vivo the specific role of these factors on the metabolism of fat cells. Recent findings have shown that both leptin and adiponectin production are affected by the increase in iron content of the adipose tissue. Thus, adipocyte specific ferroportin knock-out mice showed a significant reduction in both leptin and adiponectin plasma levels ${ }^{11,12}$. Conversely, $\mathrm{Hfe}^{-\gamma-}$ mice, with decreased hepcidin levels and increased adipocyte ferroportin expression, showed enhanced leptin production ${ }^{12}$. Although we have not found significant differences in the iron content of the adipocytes isolated from the different experimental groups, since most of the iron deposition was detected in the SVF fraction of the adipose tissue, the finding of reduced leptin production in our mouse models with elevated hepcidin levels are compatible with the above-mentioned reported data. Furthermore, mice fed an iron-enriched diet showed a strong hepcidin up-regulation in the adipose tissue and reduced visceral fat mass and insulin resistance ${ }^{10}$. Interestingly, Tmprss $6^{-1-}$ mice, which show a mild hepcidin up-regulation, displayed improved insulin sensitivity compared to wild-type mice, potentially accounting for their reduced adiposity. However, in agreement with previous data, both iron-treated Tmprss $6^{-1-}$ and Tmprss $6^{+/+}$mice, which show higher levels of hepcidin compared to untreated Tmprss $6^{-1-}$ mice in addition to an iron overload phenotype, are more resistant to insulin signaling.

Our results suggest that the reduced adiposity observed in the absence of matriptase- 2 is mainly due to the enhanced lipolysis we detected in the adipose tissue of these mice, since no differences were observed in the expression levels of genes involved in adipocyte differentiation or thermogenesis compared with wildtypes. Thus, the enhanced energy expenditure observed in the absence of matriptase- 2 was completely reverted to wild-type levels upon iron-administration, indicating an important effect of anemia in the control of energy balance. Further, it has been shown that mice treated with an oral iron chelator show higher rates of oxygen consumption and carbon dioxide production, although this treatment was not sufficient to cause a significant effect in body weight ${ }^{37}$. Therefore, altogether, these data point to lipolysis as the main cause responsible for the striking fat mass reduction observed in the absence of matriptase- 2 , independently of their hypoferremic phenotype. Moreover, the down-regulation of the lipolytic program to wild-type levels, together with the recovery of the fat mass and the increased weight gain observed in anti-HJV-treated Tmprss6 $6^{-1-}$ mice, further supports the promoting role of hepcidin and lipolysis in the obesity-resistant phenotype of matriptase-2 deficient mice. We have also considered the possibility that targeting the BMP receptor pathway via anti-HJV therapy may also down-regulate the expression of other BMP targets, such as Id1, that are increased in Tmprss $6^{-1-}$ mice ${ }^{18}$. However, different in vivo models have shown the promoting role of Id proteins in the development of obesity and fat accumulation ${ }^{38-41}$, thus ruling out a significant role of these proteins in the obesity-protection observed in Tmprss $6^{-1-}$ mice.

In conclusion, our study demonstrates that the loss of matriptase- 2 triggers lipolysis and prevents body fat accumulation upon nutrition overload. In addition, we found that the absence of matriptase-2 also protects against obesity-associated pathological conditions such as hepatic steatosis and insulin resistance. Furthermore, we demonstrate that this phenotype is dependent on the inadequate hepcidin up-regulation characteristic of Tmprss $6^{-1-}$ mice. Thus, anti-HJV-based therapy, which restored hepcidin expression to wild-type levels, completely reverted the obesity-resistant phenotype of matriptase-2 deficient mice. Our findings provide new insights regarding the role of hepcidin and iron regulation in metabolic homeostasis and adipocyte function, and suggest new strategies based on matriptase- 2 inhibition for the treatment of obesity.

\section{Methods}

Animal experiments. Tmprss $6^{-1-}$ mice have been previously described ${ }^{13}$.

Tmprss $6^{-1-}$ mice were backcrossed 9 generations to C57BL/6N background. Mouse experiments were approved by the Ethics Committee for Animal Experimentation of the Universidad de Oviedo. Iron-treated Tmprss $6^{-1-}$ mice were injected intraperitoneally with $120 \mu \mathrm{g}$ per g B.W. of iron-dextran (Sigma) for 12 weeks every other week, starting on postnatal day 15, whereas iron-treated Tmprss $6^{+/+}$mice were injected intraperitoneally with $40 \mu \mathrm{g}$ per g B.W. of iron-dextran for 20 weeks every other week, starting on postnatal day 15. For diet-induced obesity, 4-weekold Tmprss $6^{-1-}$, iron-treated Tmprss $6^{-1-}$ and wild-type male mice were fed a highfat diet (HFD) containing 60\% fat (Harlan D12492) for 20 weeks after weaning. If male mice displayed fight wounds in the course of the experiments they were removed from the experimental cohort according to pre-established exclusion criteria. No statistical method was used to estimate sample size. Body composition was analyzed by magnetic resonance imaging (MRI), using a MR Solutions MRI scanner. For the experiments based on antibody administration, 6-week-old male Tmprss $6^{-1-}$ mice under a HFD diet were injected intravenously once per week with $20 \mathrm{mg} \mathrm{kg}^{-1}$ of anti-hemojuvelin (h5F9-AM8) or anti-IgG antibodies ${ }^{36}$ for 18 weeks. Animals were randomly allocated to experimental groups. Antibodies were dissolved in a buffer containing $30 \mathrm{mM}$ histidine, $\mathrm{pH} 6.0,8 \% \mathrm{w} / \mathrm{v}$ sucrose and $0.02 \%$ Tween 80 . The injection volume administered to the mice was always below $100 \mu \mathrm{L}$. To monitor the efficacy of the antibody treatment, $100 \mu \mathrm{L}$ of blood were extracted directly from the mandibular sinus after anesthetizing the mice with isoflurane at the indicated time points in the text.

Blood and plasma parameters. For hematological determinations, complete blood counts were analyzed using Abacus junior vet equipment (Diatron labs). For blood glucose determination, blood samples were obtained from the tail vein and measured with Accu-Chek glucometer (Roche Diagnostics). For all the other measurements, blood was extracted directly from the heart after anaesthetizing the mice and collected into heparinized or EDTA-coated tubes. Blood was centrifuged at $1000 \times g$ at $4{ }^{\circ} \mathrm{C}$, and the supernatant was stored at $-80^{\circ} \mathrm{C}$ until analysis. Levels of iron, cholesterol, and triglycerides were determined in IDEXX Laboratorios (Barcelona, Spain). Plasma insulin levels were quantified by using Millipore ELISA Kits, following manufacturer's instructions. Plasma leptin levels were measured by using R\&D ELISA Kits, according to the manufacturer's protocol. Plasma ferritin levels were determined by using Abcam ELISA Kits, following manufacturer's instructions. All biochemical parameters above-mentioned were determined in plasma samples obtained from HFD-fed mice upon overnight fasting. 
Glucose and insulin tolerance test: Prior to studies, mice were fasted overnight. For glucose tolerance test, mice received an intraperitoneal injection of glucose of 1 $\mathrm{g}$ per $\mathrm{kg}$ of body weight. For insulin tolerance test, mice received an intraperitoneal injection of $0.75 \mathrm{IU}$ of insulin per $\mathrm{kg}$ of body weight. Blood glucose levels were determined with a glucometer as described above. Areas under the curve were calculated using GraphPad Prism 6.0 software.

Determination of liver triglyceride content: Liver triglycerides were determined by using the EnzyChrom Triglyceride Assay Kit from BioAssay Systems (ETGA200) following manufacturer's instructions. For sample preparation, $50 \mathrm{mg}$ of tissue were homogenized in $500 \mu \mathrm{L}$ of $5 \%$ Triton X-100. Once homogenized, samples were introduced in a water bath at $80^{\circ} \mathrm{C}$ and left inside for $5 \mathrm{~min}$ allowing them to reach $100^{\circ} \mathrm{C}$ in the water bath. We repeated this procedure twice, allowing the samples to settle at room temperature between cycles. After that, samples were centrifuged for $5 \mathrm{~min}$ at $13,000 \mathrm{rpm}$. The supernatant was recovered and diluted 8fold in MilliQ water. $10 \mu \mathrm{L}$ of this dilution was used for the assay. Samples obtained from anti-HJV-treated Tmprss $6^{-1-}$ and wild-type mice required a further dilution prior the assay.

Adipocyte and SVF isolation: Adipocytes and stromal-vascular fractions (SVF) were isolated from epididymal white adipose tissue samples. $100 \mathrm{mg}$ of this tissue were minced with surgical scissors and incubated at $37^{\circ} \mathrm{C}$ for $45 \mathrm{~min}$ with constant agitation in Hank's Balanced Salt Solution (HBSS) containing $2 \mathrm{mg} \mathrm{mL}^{-1}$ of collagenase I and II (Sigma) and $2 \%$ bovine serum albumin. After digestion, samples were centrifuged for $10 \mathrm{~min}$ at $300 \times g$ in conical tubes at $4{ }^{\circ} \mathrm{C}$. The upper fat layer containing floating adipocytes was collected into a separated tube and washed with HBSS buffer. The pellet containing the stromal-vascular fraction was resuspended in HBSS buffer and filter through $100 \mu \mathrm{m}$ nylon mesh. Both fractions were centrifuged once more for $10 \mathrm{~min}$ at $400 \times g$ at $4^{\circ} \mathrm{C}$. Isolated adipocytes and SVF fractions were snap-frozen and kept at $-80^{\circ} \mathrm{C}$.

Iron quantification: Determination of total iron content in liver, spleen and isolated adipocytes and stromal-vascular fractions obtained from the adipose tissue was carried out by using the Iron Assay Kit from Sigma (MAK025). For sample preparation, $50 \mathrm{mg}$ of liver samples, $10 \mathrm{mg}$ of spleen samples or the isolated fractions from the adipose tissue were gently homogenized in $250 \mu \mathrm{L}$ of Iron Assay Buffer. The homogenates were centrifuged at $13,000 \mathrm{rpm}$ for $10 \mathrm{~min}$ at $4{ }^{\circ} \mathrm{C}$ to remove insoluble material. $120 \mu \mathrm{L}$ of the recovered tissue supernatants were incubated with $5 \mu \mathrm{L}$ of $1 \mathrm{M}$ SDS for $5 \mathrm{~min}$ on ice. After that, samples were centrifuged again for $5 \mathrm{~min}$ at $13,000 \mathrm{rpm}$ at $4^{\circ} \mathrm{C}$ and $100 \mu \mathrm{L}$ of the recovered supernatant was used for the iron assay following manufacturer's instructions. Samples obtained from iron-treated mice required a further dilution prior the assay. Iron content was normalized to total protein content in the sample, which was quantified by the BCA assay (Pierce).

Histological analysis: White and brown adipose tissues were fixed in $4 \%$ buffered paraformaldehyde solution and embedded in paraffin by standard procedures. Paraffin sections were stained with hematoxylin and eosin (H\&E) for adipose tissue evaluation. The number of adipocytes and their mean diameter were determined in $5 \mu \mathrm{m}$ tissue sections of epididymal fat pads by computer-assisted image analysis. For each sample, 4 different fields were analyzed and 100 adipocytes were measured. For BAT droplets quantification, pictures from BAT sections stained with H\&E were analyzed with Image J software. For lipid detection, liver samples were embedded in Tissue-Tek OCT compound (Sakura Finetechnical) and stored at $-80^{\circ} \mathrm{C}$. Samples were sectioned at $10 \mu \mathrm{m}$ thickness and stained with Oil Red O. Histopathological studies were performed by investigators blinded to group identity.

RNA preparation and real-time quantitative PCR: For real-time quantitative PCR, total RNA was isolated from liver and adipose tissues with Trizol and cDNA was synthesized with the ThermoScript RT-PCR system (Invitrogen). PCR was carried out in triplicate for each sample with $100 \mathrm{ng}$ of cDNA using Taqman PCR Master Mix (Applied Biosystems) or Power SYBR ${ }^{\oplus}$ Green PCR Master Mix (Life Technologies). Hamp mRNA levels were quantified using Taqman assays (Applied Biosystems). As endogenous controls, gene expression was normalized to Actb in liver samples or Rn18s in adipose tissue samples. Primer sequences are listed in Supplementary Table 2.

Western-blot analysis: In total $20 \mu \mathrm{g}$ of white adipose tissue samples or $50 \mu \mathrm{g}$ of liver samples were separated in SDS-PAGE gels and transferred in CAPS buffer (10 $\mathrm{mM}$ 3-[cyclohexylamino]-1-propanesulfonic acid, $\mathrm{pH}$ 10.5, and 20\% methanol) onto polyvinylidene difluoride (PVDF) membranes (Millipore). Blots were blocked with $5 \%$ nonfat dry milk in TBS-T buffer $(20 \mathrm{mM}$ Tris-HCl, pH 7.4, $150 \mathrm{mM} \mathrm{NaCl}$, and $0.05 \%$ Tween 20 ) for $1 \mathrm{~h}$ at room temperature and incubated overnight at $4{ }^{\circ} \mathrm{C}$ with $5 \%$ bovine serum albumin in TBS-T buffer with rabbit polyclonal antibodies against phospho-HSL-Ser660 (Cell Signaling, cat. \#4126, 1:4000), HSL (Cell Signaling, cat. \#4107, 1:4000), and ATGL (Cell Signaling, cat. \#2138, 1:4000); and mouse monoclonal antibodies against HPRT (Santa Cruz, cat\# sc-376938, 1:1000), TfR1 (Thermo Fisher, cat\#13-6800, 1:1000) and $\beta$-actin (Sigma, cat\#A5441, $1: 20000)$. Finally, blots were incubated for $2 \mathrm{~h}$ at room temperature in $1.5 \%$ nonfat dry milk with horseradish peroxidase-coupled secondary antibodies, washed and developed with Immobilon Western Chemiluminescent HRP substrate (Millipore). Chemiluminescent images were acquired with a Fujifilm LAS3000 mini apparatus. Phospho-HSL and the corresponding loading control, the total HSL protein, were detected on the same samples run in parallel in two identical blots, after failed attempts using stripping techniques.
Statistical analysis. Results are reported by plotting independent data points or as graphic bars with mean \pm SEM. Data were analyzed for normal distribution using Shapiro-Wilk test. Differences between two groups were compared by parametric two-tailed Student's $t$ test or non-parametric Mann-Whitney test. Statistical tests were performed using SPSS, Microsoft Excel and GraphPad Prism 6.0 softwares. A value of $P<0.05$ was considered significant. Statistically significant differences are shown with asterisks $\left({ }^{\star} P<0.05,{ }^{* *} P<0.01,{ }^{* * *} P<0.001\right)$.

Data availability. Data supporting the findings of this study are available within the paper and its supplementary information files.

\section{Received: 14 August 2016 Accepted: 16 March 2018}

Published online: 10 April 2018

\section{References}

1. Theurl, I. et al. Regulation of iron homeostasis in anemia of chronic disease and iron deficiency anemia: diagnostic and therapeutic implications. Blood $113,5277-5286$ (2009).

2. Yanoff, L. B. et al. Inflammation and iron deficiency in the hypoferremia of obesity. Int J. Obes. 31, 1412-1419 (2007)

3. Bekri, S. et al. Increased adipose tissue expression of hepcidin in severe obesity is independent from diabetes and NASH. Gastroenterology 131, 788-796 (2006).

4. Nemeth, E. et al. Hepcidin regulates cellular iron efflux by binding to ferroportin and inducing its internalization. Science 306, 2090-2093 (2004).

5. Pigeon, C. et al. A new mouse liver-specific gene, encoding a protein homologous to human antimicrobial peptide hepcidin, is overexpressed during iron overload. J. Biol. Chem. 276, 7811-7819 (2001).

6. Datz, C., Felder, T. K., Niederseer, D. \& Aigner, E. Iron homeostasis in the metabolic syndrome. Eur. J. Clin. Invest 43, 215-224 (2013).

7. Guida, C. et al. A novel inflammatory pathway mediating rapid hepcidinindependent hypoferremia. Blood 125, 2265-2275 (2015).

8. Kautz, L. et al. Iron regulates phosphorylation of Smad1/5/8 and gene expression of Bmp6, Smad7, Id1, and Atoh8 in the mouse liver. Blood 112, 1503-1509 (2008).

9. Muckenthaler, M. U., Rivella, S., Hentze, M. W. \& Galy, B. A red carpet for iron metabolism. Cell 168, 344-361 (2017).

10. Dongiovanni, P. et al. Dietary iron overload induces visceral adipose tissue insulin resistance. Am. J. Pathol. 182, 2254-2263 (2013).

11. Gabrielsen, J. S. et al. Adipocyte iron regulates adiponectin and insulin sensitivity. J. Clin. Invest 122, 3529-3540 (2012).

12. Gao, Y. et al. Adipocyte iron regulates leptin and food intake. J. Clin. Invest 125, 3681-3691 (2015)

13. Folgueras, A. R. et al. Membrane-bound serine protease matriptase-2 (Tmprss6) is an essential regulator of iron homeostasis. Blood 112, 2539-2545 (2008).

14. $\mathrm{Du}, \mathrm{X}$. et al. The serine protease TMPRSS6 is required to sense iron deficiency. Science 320, 1088-1092 (2008).

15. Willemetz, A. et al. Matriptase-2 is essential for hepcidin repression during fetal life and postnatal development in mice to maintain iron homeostasis. Blood 124, 441-444 (2014).

16. Ramsay, A. J., Hooper, J. D., Folgueras, A. R., Velasco, G. \& Lopez-Otin, C. Matriptase-2 (TMPRSS6): a proteolytic regulator of iron homeostasis. Haematologica 94, 840-849 (2009).

17. Wang, C. Y., Meynard, D. \& Lin, H. Y. The role of TMPRSS6/matriptase-2 in iron regulation and anemia. Front Pharmacol. 5, 114 (2014).

18. Lenoir, A. et al. Iron-deficiency anemia from matriptase-2 inactivation is dependent on the presence of functional Bmp6. Blood 117, 647-650 (2011).

19. Finberg, K. E. et al. Mutations in TMPRSS6 cause iron-refractory iron deficiency anemia (IRIDA). Nat. Genet 40, 569-571 (2008).

20. Ramsay, A. J. et al. Matriptase-2 mutations in iron-refractory iron deficiency anemia patients provide new insights into protease activation mechanisms. Hum. Mol. Genet. 18, 3673-3683 (2009).

21. De Falco, L. et al. Iron refractory iron deficiency anemia. Haematologica 98 , 845-853 (2013).

22. Heeney, M. M. \& Finberg, K. E. Iron-refractory iron deficiency anemia (IRIDA). Hematol. Oncol. Clin. North Am. 28, 637-652 (2014).

23. Daba, A., Gkouvatsos, K., Sebastiani, G. \& Pantopoulos, K. Differences in activation of mouse hepcidin by dietary iron and parenterally administered iron dextran: compartmentalization is critical for iron sensing. J. Mol. Med. 91, 95-102 (2013)

24. Matsusue, K. et al. Hepatic steatosis in leptin-deficient mice is promoted by the PPARgamma target gene Fsp27. Cell Metab. 7, 302-311 (2008). 
25. Mottillo, E. P., Shen, X. J. \& Granneman, J. G. Role of hormone-sensitive lipase in beta-adrenergic remodeling of white adipose tissue. Am. J. Physiol Endocrinol. Metab. 293, E1188-E1197 (2007).

26. Kraemer, F. B. \& Shen, W. J. Hormone-sensitive lipase: control of intracellular tri-(di-)acylglycerol and cholesteryl ester hydrolysis. J. Lipid Res. 43, 1585-1594 (2002).

27. Babitt, J. L. et al. Bone morphogenetic protein signaling by hemojuvelin regulates hepcidin expression. Nat. Genet 38, 531-539 (2006).

28. Martinelli, N. et al. Increased serum hepcidin levels in subjects with the metabolic syndrome: a population study. PLoS ONE 7, e48250 (2012).

29. Barisani, D. et al. Hepcidin and iron-related gene expression in subjects with Dysmetabolic Hepatic Iron Overload. J. Hepatol. 49, 123-133 (2008).

30. Bridle, K. R. et al. Disrupted hepcidin regulation in HFE-associated haemochromatosis and the liver as a regulator of body iron homoeostasis. Lancet 361, 669-673 (2003).

31. Powell, E. E. et al. Steatosis is a cofactor in liver injury in hemochromatosis. Gastroenterology 129, 1937-1943 (2005).

32. Bonkovsky, H. L. et al. Non-alcoholic steatohepatitis and iron: increased prevalence of mutations of the HFE gene in non-alcoholic steatohepatitis. J. Hepatol. 31, 421-429 (1999).

33. Tan, T. C. et al. Altered lipid metabolism in Hfe-knockout mice promotes severe NAFLD and early fibrosis. Am. J. Physiol. Gastrointest. Liver Physiol. 301, G865-G876 (2011).

34. Lu, S., Bennett, R. G., Kharbanda, K. K. \& Harrison-Findik, D. D. Lack of hepcidin expression attenuates steatosis and causes fibrosis in the liver. World J. Hepatol. 8, 211-225 (2016).

35. Finberg, K. E., Whittlesey, R. L., Fleming, M. D. \& Andrews, N. C. Downregulation of $\mathrm{Bmp} / \mathrm{Smad}$ signaling by Tmprss6 is required for maintenance of systemic iron homeostasis. Blood 115, 3817-3826 (2010).

36. Kovac, S. et al. Anti-hemojuvelin antibody corrects anemia caused by inappropriately high hepcidin levels. Haematologica 101, e173-e176 (2016)

37. Cooksey, R. C. et al. Dietary iron restriction or iron chelation protects from diabetes and loss of beta-cell function in the obese (ob/ob lep-/-) mouse. Am. J. Physiol. Endocrinol. Metab. 298, E1236-E1243 (2010).

38. Patil, M. et al. Id1 Promotes obesity by suppressing brown adipose thermogenesis and white adipose browning. Diabetes 66, 1611-1625 (2017).

39. Satyanarayana, A., Klarmann, K. D., Gavrilova, O. \& Keller, J. R. Ablation of the transcriptional regulator Id 1 enhances energy expenditure, increases insulin sensitivity, and protects against age and diet induced insulin resistance, and hepatosteatosis. FASEB J. 26, 309-323 (2012).

40. Cutchins, A. et al. Inhibitor of differentiation-3 mediates high fat diet-induced visceral fat expansion. Arterioscler. Thromb. Vasc. Biol. 32, 317-324 (2012).

41. Murad, J. M. et al. Inhibitor of DNA binding 4 (ID4) regulation of adipocyte differentiation and adipose tissue formation in mice. J. Biol. Chem. 285, 24164-24173 (2010).

\section{Acknowledgements}

We thank S. Costilla (Hospital Universitario Central de Asturias) and A. Nistal (SCTs Universidad de Oviedo) for technical support on MRI scanning and image analysis, and E. Pascual, V. Loredo, A. Moyano, and R. Feijoo for excellent technical assistance. We thank M.W. Hentze for helpful comments, and B.K. Mueller and A. Popp for providing the anti-HJV antibody (Abbvie Deutschland GmbH \& Co KG) and control anti-IgG, as well as for their outstanding technical advice. We also thank Servicio de Histopatología (IUOPA) for histological studies. This work was supported by grants from Ministerio de Economía y Competitividad (Spain). A.R.F. is recipient of a Ramón y Cajal Fellowship. S.F.-R. is recipient of an FPU fellowship. The IUOPA is supported by Fundación Cajastur-Asturias.

\section{Author contributions}

A.R.F., A.J.R., G.V., and C.L.-O. designed the experiments. A.R.F., S.F.-R., C.G., and F.R. performed the experiments and analyzed the data. A.R.F. and C.L.-O. wrote the manuscript.

\section{Additional information}

Supplementary Information accompanies this paper at https://doi.org/10.1038/s41467018-03853-1.

Competing interests: The authors declare no competing interests.

Reprints and permission information is available online at http://npg.nature.com/ reprintsandpermissions/

Publisher's note: Springer Nature remains neutral with regard to jurisdictional claims in published maps and institutional affiliations.

\begin{abstract}
Open Access This article is licensed under a Creative Common Attribution 4.0 International License, which permits use, sharing, adaptation, distribution and reproduction in any medium or format, as long as you give appropriate credit to the original author(s) and the source, provide a link to the Creative Commons license, and indicate if changes were made. The images or other third party material in this article are included in the article's Creative Commons license, unless indicated otherwise in a credit line to the material. If material is not included in the article's Creative Commons license and your intended use is not permitted by statutory regulation or exceeds the permitted use, you will need to obtain permission directly from the copyright holder. To view a copy of this license, visit http://creativecommons.org/ licenses/by/4.0/.
\end{abstract}

(C) The Author(s) 2018 